\title{
A Terra esférica e o olhar transcendental na Antiguidade Greco-Romana
}

The spherical Earth and the transcendental view in Greco-Roman Antiquity

Deyse Cristina Brito Fabrício ${ }^{1}$, Antonio Carlos Vitte. ${ }^{2}$

1 Doutoranda em Ensino e História de Ciências da Terra. Universidade Estadual de Campinas, Instituto de Geociências, e-mall: deysecbf@gmall.com.

2 Docente do Instituto de Geociências, Universidade Estadual de Campinas, e-Mall: ACARlosvitte@gmall.com.

Abstract: The text proposes a study of the conception of the spherical Earth based on some models of Greek philosophy, with emphasis on Anaximander and Plato. Notes on pre-Socratic philosophy are established, whose study of nature is marked by mutations in mythology, as well as by the innovative approach of Babylonian astronomy. It is noteworthy that the intellectual activity of the philosophers of nature was part of a specific historical context, which involved the insertion of political issues, such as the advent of the polis and the resulting spatial organization. Concepts regarding of the shape of the earth are presented in the mythologies of Homer and Hesiod, as well as the contextualization of pre-Socratic and Platonic cosmologies. We end by pointing to the transcendental character of the imaginations regarding the spherical earth in the context of philosophy, and its influence on the Roman author Cicero.

\section{Manuscrito:}

Recebido: Artigo selecionado, IX Simpósio Nacional de Ensino e História de Ciências da Terra / EnsinoGE0-2019

Aceito: 07/10/2019

Citação: Fabrício, D. C. B.; Vitte, A. C,. (2019).A Terra esférica e 0 olhar transcendental na Antiguidade Greco-Romana. Terræ Didatica, 15, 1-5, e19054. doi: 10.20396/td.v15i0.8657615

Palavras-chave: História das Ciências, Cosmologia Grega, Anaximandro de Mileto.

\section{Introdução}

Olhar a Terra do espaço, de forma despregada, é um fenômeno relativamente recente. Durante milênios o sonho da contemplação do globo restringiu-se a especulações filosóficas e geográficas, quando a terra esférica acompanhou somente o âmbito da "experiência visionária" (Cosgrove, 2001, p.3). Nos dizeres de Denis Cosgrove (2001, p.IX), essas imaginações formam uma "longa genealogia" relacionada metaforicamente ao olhar panorâmico de Apolo, divindade ligada ao sol, capaz de exercer o olhar transcendental e dominante de maneira externa à Terra. A visão também pressupõe dissolução das "contingências da vida cotidiana", dando lugar a relances de contemplação e harmonia, de elevação espiritual e reflexões sobre o "lugar da humanidade" (Cosgrove, 2001, p.XI). É o esforço de abarcar toda a Terra por sua representação esférica, acompanhado da compreensão e imaginação do que há em sua superfície, um olhar apolíneo que se manifesta em imaginações geográficas de diversos contextos culturais que evidenciam, inclusive, o desejo de domínio do globo (Cosgrove, 2003, p.2).

Considerando que Cosgrove (2003) identifica a visão apolínea em concepções históricas, em imaginações ocidentais de longa data, este texto parte da Terra esférica e do olhar panorâmico na tradição greco-romana para articular proposições que remontam aos pré-socráticos, quando maneira inovadora de pensar a astronomia acompanhou os primórdios da filosofia. Para isso, abordamos inicialmente determinadas cosmologias nos poetas Homero e Hesíodo, explanando, em seguida, sobre os pré-socráticos e o cosmos geométrico que se configurou a partir de então. Percorremos a Grécia clássica, quando a terra esférica foi especificamente afirmada, finalizando a seção com o Império Romano, no sentido do que reverbera na imaginação geográfica. Concluímos com a visão de Terra esférica que se configurou na Antiguidade e suas relações com a filosofia, no âmbito do olhar apolíneo. 


\section{Desenvolvimento}

Iniciaremos a análise a partir dos poetas Homero e Hesíodo que, embora concebessem a terra plana, apresentavam indícios que permitem compreendê-la num olhar panorâmico e holístico, baseado na mitologia (Cosgrove, 2001, p.49). O matemático grego Estrabão considerou o poeta Homero o "pai da geografia" (Martin, 2005, p.15). Estudiosos, de maneira semelhante, têm situado os gérmens das descrições da Terra, como marcos da geografia clássica, nas obras de ambos os poetas, Homero e Hesíodo (Carvalho, 2006, p. XIV). Essa associação é compreensível na medida em que o papel da poesia épica na antiguidade grega, por volta do século VIII a. C., envolvia a transmissão de ideias sobre a origem do mundo (cosmogonias) e a organização da vida humana. Um relato emblemático é a elaboração do fascinante escudo de Aquiles, descrito por Homero na Iíada (Heiden, 2008). O artefato, moldado pelo deus Hefesto, tinha como intuito proteger o guerreiro grego nas pelejas contra Heitor durante o clímax da guerra de Troia (Martin, 2005, p.15). Nos fins do Canto XVIII, que retrata a configuração do Escudo, o próprio Hefesto menciona os caracteres imagéticos do artefato, que apresentava formato de disco em cinco círculos concêntricos, revelando a imagem grega de mundo (kosmou miméma) como um "universo em miniatura” (Harley \& Woodward, 1987, p.131). Heiden (2008, p.224) afirma que o Escudo era, antes de tudo, um artefato de contemplação, mais do que usos práticos. A própria descrição literária homérica envolvia esse deslumbramento, já que há interrupção na narrativa sobre as batalhas envolvendo gregos e troianos. Esse artifício narrativo, que contempla a descrição literária de uma obra de arte (ekpharasis), também apresentava um mapa cosmológico em pormenores, "uma representação moral e simbólica do universo grego" (Brotton, 2014, p.31).

No cosmos homérico, a vida cotidiana e sua representação eram parte dos desígnios divinos, capazes de subjugar e reproduzir a natureza a seu bel-prazer. Nas esferas centrais do Escudo conjugavam-se elementos celestes, como os astros, sol, lua e diversas constelações; em direção às extremidades retratavam-se atividades humanas cotidianas, tais como a guerra, a paz, a agricultura e a vida campesina (Harley \& Woodward, 1987, p.132; Brotton, 2014, p.131). O Escudo apresentava o mundo habitado, concebido metaforicamente, de forma a segmentar três cenas concêntricas: as cidades (em paz ou guerra), as terras cultivadas e as pastagens. Hefesto molda o artefato de acordo com seus dotes em metalurgia, sendo que as cinco camadas dele constituintes compunham a própria configuração do universo. Além disso, Hefesto idealiza algo cíclico como as temáticas tratadas na Ilíada, a exemplo do próprio desenrolar da vida e da natureza, integrando as estações do ano, os meses e o movimento dos astros (Heiden, 2008, p.222). Em suma, o Escudo pode ser interpretado em termos cosmogônicos, narrando a criação do universo por forças divinas e a disposição da terra num olhar panorâmico.

De maneira semelhante, a obra Teogonia de Hesíodo (1996) diz respeito à configuração do mundo físico, bem como à origem dos humanos $\mathrm{e}$ das divindades (Kragh, 2007, p.7). O poema constrói imagens da cosmogonia grega, com a situação de Caos inicial que, a partir de uma "massa informe" (Brotton, 2014, p.32), impulsiona o nascimento de gerações de divindades e Titãs, que rivalizam a soberania e o controle do universo. Em disputas sucessivas, a ordem do mundo culmina com o governo de Zeus, que por ardil destrona seu pai, Cronos, devorador dos próprios filhos. Cronos, por sua vez, destronara e castrara seu pai Urano (Hesíodo, 1996), enfatizando, ainda, a questão sequencial que leva ao estado de organização do mundo. $\mathrm{Na}$ épica há quatro divindades primordiais, que compartilham sentimentos e ações correlatas aos seres humanos (Pajares, 1988, p.13): Caos, Gaia (Terra), Tártaro (abismo) e Eros. Essa mitologia exprime a organização do mundo, culminando com o governo de algum ente. No caso da Teogonia, esse poder está nas mãos de Zeus, que se constitui enquanto autoridade a partir da sucessão de acontecimentos (Vernant, 1973, p.173).

A obra de Hesíodo, por definição, esteve marcada por visão cosmogônica de mitos de criação do universo a partir de divindades (Teogonia). Esse tipo de explicação sofrerá transmutações, primordialmente com os pensadores da Escola Jônica de Mileto (século VI a. C), nomeados "filósofos da natureza”. Kragh (2007, p.13) afirma que essa contribuição pode corresponder a uma primeira revolução científica, dada a importância das abordagens sobre a organização do mundo que sobrevieram, sem adotar a mitologia como cerne. Segundo Martin (1972), a região da Ásia Menor constituía um centro comercial permeado pela divulgação de informações geográficas. Havia, ainda, influências da geometria e matemática babilônicas. Nesse sis- 
tema, a base da transmissão de conhecimentos era função dos escribas, que computavam observações astronômicas relacionadas à própria economia e dinâmica social. Em última análise, os escribas estavam a serviço do rei, que era o mandante da vida terrena e celestial, um intermediário que tinha como incumbência acompanhar os movimentos dos astros como prenúncio do destino de seus súditos. Era parte, portanto, de uma religião astral, com calendário primariamente religioso (Vernant, 1973, p.156). Por outro lado, a Escola de Mileto é conhecida pelas proposições filosóficas fundamentais, dentro de um "arranjo significativo" (Martin, 1972, p.16) com base no raciocínio para ordenar o cosmos conforme princípio originário, que não coadunasse com as gerações de divindades ou com a astrologia a determinar o destino da humanidade (Martin, 1972. p.18).

Explicações ambíguas do nascimento da humanidade nos primeiros relatos míticos gregos da Criação contrastam com as explicações científicas e naturalistas da "ordem das coisas" que começaram a surgir no século VI a.C. na cidade jônica de Mileto (na atual Turquia), onde floresceu um grupo de pensadores que apresentavam um argumento de aspecto científico para explicar a Criação (Brotton, 2014, p.33-34).

Pajares (1988, p.17) afirma que a filosofia pré-socrática correspondeu a um salto no sentido de questionar as respostas míticas, embora não tenha sido algo automático ou um rompimento definitivo. O ponto de partida dos filósofos foi a poesia hesiódica, com a particularidade de que, em vez de expressar algo concreto, definido in illo tempo$r e$, introduzia-se a especulação abstrata, inusitada para os pensadores do século VI a. C. (Pajares, 1988, p.12). Outro traço de destaque é que, nos hinos hesiódicos, porque ligados a mitologias, as entidades e deuses são dotados de sentimentos antropomórficos, inclusive a poética mãe Gaia (Pajares, 1988, p.13). De outra parte, para os referidos pré-socráticos, os elementos naturais passam a ser descritos de maneira despersonalizada (Pajares, 1988, p.16). Ambas as formas de explicação da natureza, filosofia e mitologia, identificam a ordem universal na possibilidade de apreendê-la. Porém, o mito tendia a organizar o mundo conforme ideias preestabelecidas, anunciando uma única possibilidade de ajuste em meio ao caos, sob pena de consequências drásticas à humanidade. Contrastando com as diferentes interpretações que o mito viabiliza, a filosofia pressupõe uma leitura com caracteres unívocos acerca da ordem atual do mundo. Enquanto o pensamento mitológico lida com acontecimentos concretos, a filosofia insere questões ligadas à abstração, em que o presente é portador de historicidade e não se equaliza a uma cópia do passado; o tempo dos acontecimentos e fenômenos é contemporâneo e não foi explicado com base numa época remota e sacralizada (Pajares, 1988, p.13).

Os filósofos jônios corresponderam a uma "mudança paradigmática" (Kragh, 2007, p.13) nas maneiras de explicar as origens do cosmos, descrito como harmonioso e regular. No campo dos contextos históricos, Vernant (1973, p.159) explica que entre Hesíodo e Anaximandro ocorre o processual surgimento da pólis grega e isso implica mutações na forma como a comunidade se organizava. A ágora constitui, por excelência, o local central em que as discussões públicas são explicitadas de forma igualitária, ao menos em nível da restrita cidadania. A esses fatores atrela-se o próprio desenvolvimento da astronomia jônia, em termos de imagem de mundo. A pólis não era regulamentada por uma figura superior real, com acesso privilegiado aos desígnios divinos. Era necessário que os cidadãos se apresentassem com argumentações ao centro para que o debate fosse aberto (Vernant, 1973, p.162). Assim, o saber da natureza passou por dessacralização (Vernant, 1973, p.162) de forma concomitante à busca de organização da pólis.

Quando o filósofo Anaximandro de Mileto postula que a Terra imóvel se configura numa "coluna truncada no meio cosmo" (Vernant, 1973, p.159), também está indicando a maneira como a própria pólis se organizava, simetricamente, e não com ordens hierárquicas. A relevância é que a espacialidade passou a ser geométrica e não mais aritmética, como na astronomia babilônica. Instaura-se a tradição matemática nas cosmologias, com aspirações às simetrias celestial e terrestre, em que a Terra estaria no centro do cosmos, sem necessidade de que fosse sustentada por um elemento que diferisse dela mesma. Para Anaximandro, a Terra era concebida em formato de cilindro, suspensa "no centro de um cosmos simétrico em perfeito equilíbrio" (Brotton, 2014, p.35). Engendra-se, pois, a concepção esférica de universo no seio da pólis, em que todos os pontos estavam igualmente dispostos em relação ao centro. $\mathrm{Na}$ astronomia, isso explicaria a imobilidade e estruturação da Terra no modelo espacial

C) Terrae Didat. $\quad$ Campinas, SP

\begin{tabular}{l|l|l} 
v.15 & $1-13$ & $\mathrm{e} 0190 \mathrm{xx}$
\end{tabular} 2019 
geométrico, adotando o círculo como a "forma mais perfeita" (Vernant, 1973, p.163).

As informações que nos chegam atestam que a forma circular e simétrica do Universo foi mencionada por filósofos situados após Anaximandro, a exemplo da enigmática escola fundada por Pitágoras de Samos, em Crotona. Nesse sentido, afirmar a esfericidade da Terra fez parte das explicações filosóficas. Por volta de 430 a.C., os pitagóricos mencionavam a Terra como esférica, mesmo que de forma obscura e inovadora à época, centrados em motivos místico-religiosos acerca da perfeição geométrica. O cosmos pitagórico provinha da ideia grega de harmonia, em que os números são considerados mágicos (Pajares, 1988, p.73). As teorias da perfeição dos números viriam a designar a relação entre o cosmos divino e a perfeição da alma imortal, capaz de transcender a ordem física imediata e atingir a salvação (Pajares, 1988, p.76). Um dos propósitos da Escola de Crotona era a busca da verdade por meio da contemplação (theoria) do cosmos, especificamente o conjunto matematicamente ordenado das coisas para alcance da purificação espiritual e transcendência (Pajares, 1988, p.72).

Embora anteriormente intuído pelos pitagóricos, foi Platão o primeiro a afirmar claramente a esfericidade da Terra (Brotton, 2015, p.31), dando continuidade à ideia de transcendência da alma. $\mathrm{O}$ discípulo de Sócrates aborda várias questões astronômicas em seus escritos, apequenando o papel das observações diretas para dar lugar a atitudes idealistas na apreensão do cosmos (Kragh, 2007, p.19). Por meio do diálogo intitulado Fédon (Platão, 2012), o filósofo contempla os últimos ensinamentos de seu mestre, já no cárcere. Sócrates explana sobre a imortalidade da alma e seu temporário aprisionamento mediante as necessidades, paixões e vícios do corpo. A existência das formas perfeitas no mundo das ideias, contemplada somente pela alma, dá ensejo à compreensão de que as coisas na Terra não passam "cópias simplórias" (Martin, 1972, p.23). Por esse prisma, as ideias geográficas platônicas preconizam que o mundo está sob degeneração e que a Terra ideal e eterna só pode ser contemplada pela alma, não pelo corpo perecível. "Mas a Terra ela mesma é pura e está no céu puro onde se encontram os astros" (Platão, 2012, p.125). Ademais, o Fédon introduz a temática do formato da Terra quando se refere ao destino das almas e sua descida ao Hades, após julgamento (Platão, 2012, p.124).

A construção dos diálogos socráticos reverbera na constatação da perfeição do cosmos, no senti- do teórico, acessível de forma plena somente pela contemplação da alma e de suas reminiscências, anteriores ou posteriores ao período de aprisionamento imposto pelo corpo. Desse modo, olhar a Terra de maneira transcendental, "esse ideal irresistível" (Brotton, 2015, p.32) que alimentou as "subsequentes imaginações geográficas acerca do Globo" (Brotton, 2015, p.31), está diretamente atrelado ao contexto da morte iminente de Sócrates e à contemplação das almas dos abençoados (Platão, 2012, p.129). Vista de forma transcendente, a Terra esférica e harmônica dos últimos apontamentos do Fédon foi demonstrada por Platão (2012) em termos de simetria e a consequente posição geocêntrica, que assumem marcada importância na explicação da teoria do mundo das ideias. Mais do que ordem e controle, a visão do globo é traduzida em ideias de unidade, perfeição e até de divindade (Cosgrove, 2001, p.5). O filósofo referido argumenta que a Terra assume posição central não porque esteja envolta por alguma substância elementar e, sim, em virtude da própria relação simétrica, prescindindo de algum elemento que a sustente, assim como já postulara Anaximandro.

[...] Estou convencido de que, em primeiro lugar, se a Terra é esférica e está no centro do céu, prescinde do ar ou de qualquer outra força semelhante para impedir sua queda, bastando seu próprio equilíbrio e a natureza homogênea do céu em todos os lados para conservá-la no lugar; de fato, um corpo que se mantém em equilíbrio e se encontra situado no centro de alguma coisa homogênea não apresenta a tendência de alterar sua inclinação em qualquer direção, permanecendo sempre na mesma posição. Eis aí a primeira coisa de que estou persuadido (Platão, 2012, p. 124-125).

De forma semelhante, o olhar apolíneo transcendental está evidente na passagem intitulada "Sonho de Cipião", do texto República (51 d. C), escrito pelo orador romano Cícero. O general Cipião exprime suas conquistas na África de forma visionária, especialmente na cidade de Cartago. $\mathrm{Na}$ língua latina, essa condição espiritual elevada e imaginativa recebe o nome de somnium, proporcionando a vivência da harmonia e da beleza matemáticas, traduzida na forma esférica. Macróbio (2005), autor romano tardio (século IV d.C.), realizou comentários sobre tal excerto, desenvolvendo ideias de filósofos que enunciam a harmonia dos números revelada através da música no sonho de ascendência 
cósmica. Para Cosgrove (2001, p.21), este sonho se traduz no próprio olhar de Apolo, firmado na harmonia entre os mundos celestial e terrestre. Tal contemplação é revelada no cosmos estoico, que minimiza a existência humana se comparada ao esplendor do vastíssimo universo (Cosgrove, 2001, p.6). No contexto romano, pretendeu-se alastrar a supremacia do Império em todo mundo habitado, o orbis terrarum ou espaço global. A cidade de Roma coincidia com o centro do mundo conhecido, de onde exercia seu poderio. As moedas vinham com a chancela do imperador e o formato circular fazia analogia ao globo. O mesmo se pode afirmar das esculturas de Júlio César portando um globo em que se representava o ecúmeno. Era a tentativa de tornar o imperador um ente semi-divino, descendente de Apolo (Cosgrove, 2003, p.52). Desse modo, além de constituir jornada filosófica, o voo panorâmico apolínico permitiu contemplar a Terra esférica, vinculando a transcendência da alma ao sonho ocidental de um império global (Cosgrove, 2001, p.50).

\section{Conclusões}

Cosgrove (2001, p.49) pontua que, em termos mitológicos, tanto no homérico Escudo de Aquiles quanto na ordem imposta por Zeus, em Hesíodo, identifica-se a visão apolínea, mesmo que a terra não seja concebida como esférica. No contexto dos filósofos pré-socráticos, com Anaximandro ocorre inovação no seio da pólis, pois a astronomia babilônica se vinculará à geometria para possibilitar a ideia de esfericidade do universo. A Terra esférica será formalmente admitida no diálogo platônico Fédon, como um voo panorâmico, que se relaciona à imortalidade das almas e ao próprio contexto da condenação de Sócrates. A visão transcendental também será influente e basilar nos impérios globais, que aspiravam ao domínio do globo, algo atestado em Cícero, autor latino estoico, em sua obra República. A herança das concepções e representações do globo, bem como do olhar apolíneo, não se encerram na Antiguidade, porém, o recorte temporal foi aqui estabelecido para a identificação de momentos seminais, relacionados a seus contextos históricos sobre o ideal transcendental da Terra esférica.

\section{Agradecimentos/Apoio}

Conselho Nacional de Desenvolvimento Científico e Tecnológico (CNPq)

\section{Referências}

Brotton, J. (2014). Uma história do mundo em doze mapas. Rio de Janeiro, RJ: Zahar.

Carvalho, M. S. de. (2006). A geografia desconhecida. Londrina: EDUEL.

Cosgrove, D. (2001). Apollo's eye: a cartographic genealogy of the earth in the western imagination. Baltimore, MD: Johns Hopkins University Press.

Harley, J. B.; \& Woodward, D. (1987). The History of Cartography. Chicago, Illinois: The University of Chicago Press. v. 1.

Heiden, B. A. (2008). Homer's cosmic fabrication: choice and design in the Iliad. Oxford [Inglaterra]: Oxford University Press.

Hesíodo (1996). Teogonia. Niterói, RJ: UFF.

Kragh, H. (2007). Conceptions of cosmos: from myths to the accelerating universe: a history of cosmology. Oxford: Oxford University Press.

Macrobio, A. T. (2005). Comentarios al Sueño de Escipión. Madrid: Siruela.

Martin, G. J (1972). All possible worlds: a history of geographical ideas. $4^{\text {th }}$ ed. Indianapolis: Odyssey Press.

Pajares, A. B. (1988). De Tales a Democrito: fragmentos presocraticos. Madrid: Alianza.

Platão (2012). Fédon (ou da alma). Tradução, textos complementares e notas: Bini, E. São Paulo: Edipro.

Vernant, J. P. (1973). Mito e pensamento entre os gregos: estudos de psicologia histórica. São Paulo, SP: Difel: Edusp, 1973. 